Article

\title{
Pragmatism and the Limits to the European Parliament's Strategies for Self-Empowerment
}

\author{
Carlos Closa Montero ${ }^{1,2, *}$, Felipe González De León ${ }^{1}$ and Gisela Hernández González ${ }^{1}$ \\ ${ }^{1}$ Institute of Public Goods and Policies, Spanish National Research Council, Spain; E-Mails: carlos.closa@csic.es (C.C.M.), \\ falfonso.gonzalez@csic.es (F.G.D.L.), gisela.hernandez@csic.es (G.H.G.) \\ ${ }^{2}$ School of Transnational Governance, European University Institute, Italy \\ * Corresponding author
}

Submitted: 9 March 2021 | Accepted: 3 June 2021 | Published: 13 August 2021

\begin{abstract}
Despite the European Parliament's (EP) growing role, its influence and scrutiny capacity remain considerably weaker than the role traditionally reserved for parliaments in economic and fiscal policy decision-making at the national level. The EP has exploited any opportunity to enhance these powers: In particular, the EP has a record of using crisis and extraordinary situations to expand its role beyond the formal prerogatives given to the institution. Following this literature, this article examines the role and influence of the EP on economic and fiscal policy, focusing on the response to the Covid-19 crisis. Negotiation of the Recovery and Resilience Facility presents an auspicious area to analyse the strategies implemented by the EP to influence the outcome and reinforce its position in EU economic governance. The article will look specifically at the formal and informal mechanisms used by the EP during the crisis to expand its powers. Moreover, it utilises a research design that combines the content analysis of several official/public documents and statements from key members of the European Parliament (MEPs) involved in economic policy.
\end{abstract}

\section{Keywords}

accountability; Covid-19; economic governance; economic policy; empowerment; European Parliament; negotiation

\section{Issue}

This article is part of the issue "Rising to a Challenge? Ten Years of Parliamentary Accountability of the European Semester" edited by Eric Miklin (University of Salzburg, Austria), Aleksandra Maatsch (University of Wroclaw, Poland) and Tomasz P. Woźniakowski (Hertie School, Germany).

(C) 2021 by the authors; licensee Cogitatio (Lisbon, Portugal). This article is licensed under a Creative Commons Attribution 4.0 International License (CC BY).

\section{Introduction}

The prerogatives and accountability capacities of the European Parliament (EP) have expanded since the 1990s, peaking with the Treaty of Lisbon (Woźniakowski et al., 2021). The EP's agency is said to have played a role in this expansion, for instance, in introducing de facto powers in certain aspects of Economic and Monetary Union (EMU) governance and trade policy (Meissner \& Schoeller, 2019). Similarly, the EP has also obtained scrutiny capacities over the Commission (Brandsma, 2016), the Council (Wille, 2016), the European Council (EUCO; Van de Steeg, 2009), European agencies (Busuioc, 2013), and even over the
Brexit negotiations (Closa, 2020). However, the EP has also failed in other attempts to extend its powers. Whilst the Treaty of Lisbon presented the EP as an 'equal' to the Council, the EP found itself sidelined in the design of the response to the Eurozone crisis (Bressanelli \& Chelotti, 2016, 2018; Fabbrini, 2013; Puetter, 2012). Thus, the European Stability Mechanism (Rittberger, 2014) or the Macroeconomic Imbalance Procedure (Schoeller \& Héritier, 2019) are examples of resounding failures in the EP's attempts to expand its powers.

The Covid-19 crisis represents a new opportunity for the EP to expand its powers to a new area. Thus, in response to the crisis, several new policy instruments 
were created, among which the Recovery and Resilience Facility (RRF) stands out. The RRF is part of a package of funds dedicated to fight the pandemic, the NextGenerationEU ( $€ 750 \mathrm{bn}$ ), which includes the RRF ( $€ 672.5$ bn), ReactEU ( $€ 47.5$ bn), InvestEU ( $€ 5.6$ bn), Horizon Europe ( $€ 5$ bn), Rural Development ( $€ 7.5$ bn), Just Transition Fund ( $€ 10 \mathrm{bn})$, and RescEU ( $€ 1.9 \mathrm{bn}$ ). The unprecedented size of the package, the combination of grants and loans, and the fact that the issuance of EU debt finances the instrument make the Facility a major development. Hence, the RRF negotiations represent an excellent case study to examine the strategies deployed by the EP to acquire new powers and its ability to influence the outcome.

Building on the literature on the self-empowerment of the EP, we investigate whether and why the EP acts as a maximiser of its own powers. To that end, we address two questions: (1) To what extent (if any) did the EP increase its powers or influence during the RRF negotiations? and (2) Why did the EP fail to acquire all the powers and influence it demanded? In doing so, we argue that the EP implemented a set of strategies in order to expand its powers and influence during the RRF negotiations. However, the use of those strategies was conditioned by a series of external factors that ultimately limited the ability of the EP to maximise its powers. In this context, the EP opted to settle for smaller concessions than those originally demanded.

To tackle these questions, first, we try to assess the level of the EP's success in introducing its policy agenda and extracting new prerogatives (empowerment via policy and governance). For this, we rely on the comparison of different legislative documents, complementing this with interviews with members of the European Parliament (MEPs). Second, we present empirical evidence derived from 13 interviews with key decisionmakers involved in the negotiations and a wide range of official documents to analyse the strategies used by the EP in its attempts to expand its powers and the limitations it faced along the way.

Our findings suggest that the EP obtained limited gains in terms of accountability and scrutiny capacities in the RRF, but conversely extracted important policy concessions. Moreover, we confirm that the EP sought its own empowerment through the deployment of several strategies destined to reinforce its bargaining position. This is in line with previous studies that argue that the empowerment can be explained through rational institutionalist mechanisms. Nevertheless, rather than a pure power maximiser, willing to pursue its empowerment at all costs, from the negotiations emerges the picture of a pragmatic negotiator. Thus, the EP used several strategies to advance its preferences and extract concessions, whether these refer to policy or governance. However, when faced with a series of adverse conditions, the EP preferred to settle for smaller gains rather than embarking on a costly political confrontation in order to maximise its powers.
The large set of resources under negotiation facilitated the negotiation over policy outcomes, while the lack of predisposition to yield governance instruments that the EP perceived in the Council represented an obstacle for the EP. Moreover, the costs associated with implementing hard strategies (e.g., delaying the approval or vetoing the package), the lack of support from the Commission, and the limits to intergroup consensus concur to explain the pragmatic approach taken by the EP.

\section{The Empowerment of the EP}

Since the late 1980s and early 1990s, the EP has increased its powers across several policy areas (Hix \& Høyland, 2013). Thus, examples of such empowerment can be found in trade policy (Meissner, 2016; Ripoll Servent, 2014; Rosén, 2016), Brexit negotiations (Closa, 2020), political and technocratic appointments (Hix, 2002; Schoeller \& Héritier, 2019) or financial supervision and economic governance (Fasone, 2014; Rittberger, 2014).

Within this context, the EP has systematically attempted to maximise its prerogatives and accountholding powers (Bressanelli \& Chelotti, 2016; Héritier, 2017; O'Keeffe et al., 2016; Rittberger, 2014). Sometimes, concessions in these areas partially compensate the EP for its lack of substantial influence in the design of key legislation (Dionigi, 2020; Dionigi \& Koop, 2019). Additionally, these ad hoc concessions may create an incrementalist process (Benedetto \& Hix, 2007; Hix, 2002), which results in the EP using the new prerogatives to propose an expansive interpretation of the rules to further extend its powers.

Some scholars explain the empowerment of the EP by focusing on agency itself (Farrell \& Héritier, 2007; Héritier et al., 2015; Hix, 2002; Meissner \& Schoeller, 2019). These authors understand the EP as a rational power maximiser, which actively seeks to expand its role through different means and strategies. For instance, assuming asymmetry of information and imperfect contract theories, Hix (2002) argues that one way through which the EP has extended its power is by moving quickly to present an expansive interpretation of the existing de jure rules. This allows the EP to create de facto practices, which are then accepted by other actors and formalized as formal rules in subsequent reforms. Prolonging this line of argument, other authors (Closa, 2020; Schoeller \& Héritier, 2019) also show how the EP uses all the resources and prerogatives at its disposal in order to obtain new powers.

As an alternative to this pure rational institutionalist approach, another set of authors (Goetze \& Rittberger, 2010; Pollack, 1997, 1999; Rittberger, 2012, 2014) assign less weight to the agency component and suggest that behind the empowerment of the EP there is an ideological commitment to reduce the democratic deficit. Thus, they emphasise the normative pressure to empower the EP and argue that the expansion of the role of the EP also responds to the need to increase the legitimacy of 
the decision-making process. Hence, the empowerment can also be promoted by persuasion or driven by public demands.

In line with the rational institutionalist approach, we argue that the EP behaved as a strategic actor during the RRF negotiations, seeking to increase its powers and influence by exploiting all the resources at its disposal through the use of several strategies. This repertoire includes veto threats, issue linkage, timing control, intergroup consensus, and interinstitutional alliances.

Firstly, threatening to veto outcomes if its demands are not accepted gives the EP leverage vis-à-vis any other negotiating actor. Therefore, the EP has waived its veto in areas such as the appointment and investiture of the Commission (Moury, 2007) or in the ratification of agreements such as the SWIFT interim agreement (from 2010) and the Anti-Counterfeiting Trade Agreement (from 2012; Devuyst, 2013; Shaohua, 2015). Similarly, it has also used this successfully during the negotiation of the Brexit agreement (Closa, 2020).

Secondly, the EP has also used issue linkage strategies repeatedly, seeking to connect areas where the institution has more powers with others where it counts on less (formal) powers (Héritier, 2017; Schoeller \& Héritier, 2019). Since the bargaining position of the EP is stronger when co-decision or consent are required (O'Keeffe et al., 2016), the EP may seek to link issues where these procedures apply with others not covered by them. Examples of this can be found in budget negotiations (Alfé, 2007) and economic governance (Héritier et al., 2015).

Thirdly, the EP can also use to its advantage the timing and urgency of a decision to improve its negotiating position. Thus, the EP can seek to delay a decision to gain leverage or speed it up in attempt to set the agenda. Héritier et al. (2019) present several examples where the EP recurred to a delaying strategy. However, timing can also play against the EP. During the Eurozone crisis, the need for a prompt response to calm the financial markets and avoid negative effects favoured intergovernmental or technocratic bodies and relegated the EP (Bressanelli \& Chelotti, 2016).

Fourthly, the EP can more easily obtain concessions from other institutions when the main political groups agree on a certain position and show unity in their action (Closa, 2020; Costello \& Thomson, 2013; Kreppel, 1999; O'Keeffe et al., 2016). Intergroup consensus tends to be used as a complementary strategy and as a way of reinforcing the bargaining position. Thus, it can be a power instrument to reinforce the credibility of a veto threat, display force, or facilitate the use of an expansionary interpretation of the rules (issue linkage).

Finally, the EP may also seek to establish alliances with European institutions, typically the European Commission (Closa, 2020; Rosén, 2016), to reach certain policy goals. These institutions are likely to cooperate to increase their power and influence based on a common interest and a shared integrationist or pro-European identity.
This repertoire follows the list of strategies from Héritier et al. (2019) to obtain formal and informal institutional changes. Nonetheless, the repertoire above does not exhaust all possible strategies, leaving out wellknown ones such as the threat of the European Court of Justice, unilateral first moves, the use of external pressure, etc. Instead, we have sought to narrow the list to those relevant to our case (a comprehensive list in Héritier et al., 2019). Similarly, it should also be mentioned that the EP rarely uses any of the strategies in isolation but rather combines them. Thus, several examples display a combination of strategies with different degrees of success, e.g., interinstitutional alliances with veto threats (Closa, 2020) or delaying strategies and issue linkage (Schoeller \& Héritier, 2019).

Drawing on this theoretical framework, we argue that the EP sought to increase its powers in the RRF negotiations through the deployment of several bargaining strategies. Nevertheless, these strategies faced a series of limitations that led the EP to settle for smaller gains instead of recurring to harder (and more costly) strategies.

\section{Methodology and Data}

The outcome to be explained is the empowerment of the $E P$ in the case of the RRF (i.e., concessions and changes made in the text to include the priorities of the EP concerning governance). Additionally, we also present concessions to EP demands concerning policy. Capturing the influence of the EP in the negotiations is a very difficult task, leading scholars to tackle this challenge through different approaches and operationalisations. For instance, Meissner and Schoeller (2019) designed an index of empowerment for the EP, based on four types of empowerments and using evidence extracted from legislative texts and interviews.

Several factors explain the difficulty to assess the empowerment of the EP in the case of the RRF. First, the large number of exchanges held at each stage of the process makes it hard to identify where an idea is coming from and capture agenda-setting effects (e.g., the Commission knowing it needs to secure the support of the EP and that the Council is likely to incorporate their preferences and proposal in the first draft). Second, several documents and reports are negotiated in different fora (i.e., between political groups, committees, plenary), making it more difficult to keep track of changes. Third, in parallel to the changes promoted by the EP, decisions taken by other actors during the process may be incorporated into the documents prepared by the EP. Hence, changes need to be disentangled. Finally, when examining legislative documents, it is necessary to take into account their connection with other pieces of legislation and that some amendments may be included only to obtain concessions in other areas.

In light of these challenges, we use a crude but comprehensive approach to assess the empowerment and 
influence of the EP. On the one hand, we compare the Commission proposal (European Commission, 2020), the draft resolution of the EP (maximum position; EP, 2020), and the final text (outcome) agreed on with the Council (Regulation of the EP and of the Council of 12 February 2021, 2021). On the other, we complement this initial assessment with the main changes observed in other legislation connected with the RRF, the Own Resources Decision (ORD; Council Decision of 14 December 2020, 2020), the Multinational Financial Framework (MFF) regulation (Council Regulation of 17 December 2020, 2020), and the conditionality on the rule of law regulation (Regulation of the EP and the Council of 16 December 2020, 2020). Finally, given that comparison of the text can be misleading, as some amendments may be introduced for opportunistic reasons and might be considered unlikely to pass by the proponents themselves, we refine the assessment with the evidence extracted from the interviews.

We define empowerment as the expansion of the formal prerogatives of the EP and the increase in the influence of the EP over the policy implemented. Consequently, we focus on the empowerment observed in two areas: governance and policy. By governance, we understand this as the institutional mechanisms and procedures that allow the EP to participate in the RRF and hold other institutions accountable. Meanwhile, by policy, we understand this as the ability of the EP to shape or alter the goals, funds, and priorities of the RRF. Finally, we treat the EP as a unit given that as an institution it passes legislation, issues official statements, and engages in negotiations with other actors based on the common position set by the groups.

Evidence for explaining why and how empowerment happened comes from two sources. On the one hand, we have conducted 13 interviews with MEPs and Commission officers (see the list of interviews in the Supplementary File II). We transcribed and coded the interviews (see codebook in the Supplementary File III). To verify that the EP has used any of the strategies, evidence (interviewees and documentary sources) should be consistent and back the use of each strategy. We set as a test that at least two interviewees utter statements that interpretatively contain references to these strategies. In line with best practices for transparency in qualitative research (Closa, 2021), we include a detailed research implementation report (Supplementary File I) plus the list of interviewees (Supplementary File II), the Codebook (Supplementary File III), and the output of the Atlas.ti@ analysis (Supplementary File IV). Given word count limitations, we report in Supplementary File VII all quotations used to substantiate interpretation in the findings section. In the text, the number in brackets redresses towards the same number in Supplementary File VII.

On the other hand, we compiled 63 press releases issued by the EP (included in the Supplementary File) regarding negotiations of the MFF-RRF throughout the year 2020 (up until November 30). Additionally, we supplement these documents with parliamentary resolutions concerning the MFF-RRF (approved between 2018 and 2020) and with statements from key MEPs involved in the negotiations, which are included in press documents or open letters. Given that the EP opted for carrying out a very public negotiation, communicating its demands in several public documents, these documents constitute a reliable source to identify the position of the EP, the arguments it uses, and the strategies it implements (see Supplementary File VI). Moreover, they allow us to observe how the negotiations evolved over time.

\section{Findings}

\subsection{The Influence of the EP on the Negotiations}

Table 1 shows the main powers and policy concessions obtained by the EP in the negotiations of the RRF regulation. In terms of governance, the provisions focus mainly on guaranteeing access to information, the establishment of mechanisms enhancing accountability and scrutiny capacities of the EP, and the creation of procedures that facilitate assessment of the implementation. In terms of policy, the EP was able to influence spending priorities significantly, shape the policy agenda behind the RRF, and define the criteria for assessment of the recovery plans. The reinforcement of the EP's role refers not only to the outcome but also to the negotiating process itself: initially, the legal basis and, hence, the procedure for creating the new recovery instrument was unclear. Options included Article 122 TFEU or Article 352 TFEU, and there were questions on its compatibility with Articles 310 and 311. In the end, the European Recovery Instrument (the funds behind the RRF) was established via Article 122, which does not reserve any role for the EP. Therefore, being part of the negotiating table from the beginning was already a victory for the EP, which could have been excluded from the process (or, at least, it was not clear that its inclusion was inevitable).

Whilst the concessions obtained improved the role assigned to the EP in the initial proposal, they fell short of its most ambitious aspirations. In its public assessment, the EP valued in particular the establishment of a new procedure (the dialogue) "in order to agree on the budgetary implications of any proposed new legal act on the basis of Article 122" (EP press release November 10). Most MEPs and Commission officials share this positive evaluation of the governance outcome (1 in Supplementary File VII), whilst others do not concur (2). Additionally, some of them reconcile both positive and negative judgements (3) and recognize that some of the amendments regarding the role of the EP were unrealistic (4). Finally, it should also be noted that up to seven MEPs argued that the real discussion on the role of the EP in the governance of the RRF is yet to come (5).

Institutions treated RFF negotiations in connection with other budgetary issues, such as the ORD, the MFF 
Table 1. Powers and policy concessions obtained by the EP in the RRF regulation.

\begin{tabular}{llll}
\hline Area & Power & Concessions Obtained by the EP & $\begin{array}{l}\text { Concessions Not Obtained by the EP or } \\
\text { Watered Down }\end{array}$ \\
\hline Governance & $\begin{array}{l}\text { Access to } \\
\text { information and } \\
\text { transparency }\end{array}$ & $\begin{array}{l}\text { Broad access to information and on } \\
\text { equal conditions as the Council. }\end{array}$ & $\begin{array}{l}\text { Access to the information on the main } \\
\text { discussions of the Council and } \\
\text { its bodies. }\end{array}$ \\
& $\begin{array}{l}\text { Right to be informed and to invite the } \\
\text { EC to discuss the suspension of the } \\
\text { funds on the basis of sound economic } \\
\text { governance. }\end{array}$ & \\
& $\begin{array}{lll}\text { The EC shall present a review report } \\
\text { and scrutiny } \\
\text { capacity }\end{array}$ & $\begin{array}{l}\text { on the implementation by July 2022. } \\
\text { EP may invite the EC to discuss it. }\end{array}$ & $\begin{array}{l}\text { The Recovery and Resilience Dialogue } \\
\text { does not cover representatives of } \\
\text { member states, the Council and its } \\
\end{array}$ \\
& EC must present preliminary & bodies, or the Eurogroup.
\end{tabular}

assessment on progress towards the milestones in the RRPs and the EP may invite it to obtain more information.

Establishment of the Recovery and Resilience Dialogue. Entitles the EP to invite the EC every two months to get information.

EP may issue resolutions in the framework of the recovery dialogue and the EC shall take them into account.

EC must present an annual report on targets and disbursements.

Shorter deadlines for the independent evaluation report on the implementation and the ex-post evaluation.

Delegated powers given to the EC significantly restricted.

EC must review the application of the mechanism in 2024 or if there is a major change.

Procedural Establishment of a scorecard to assess
mechanisms the progress of the RRPs. Results will be public.
Quarterly reports from member states within the European Semester process in which EP may invite member states to discuss progress on RRPs.

Biannual reports on implementation, targets and disbursements. These reports also need to include repayment details.

Biannual reports from independent fiscal institutions and their assessment of the costs.

Biannual report on implementation was limited to one.

EC needs to appear before EP after negative assessment of RRPs or after negative assessment of its amendment.

Ability to monitor EC's spending decisions and the creation of a database with quarterly information.

EP may appointment some of the experts assisting the EC in assessment of the advances or preparation of reports.

Two reviews of the regulation (in 2022 and 2026).

Independent fiscal institutions must validate total costs of the plans.

Connection of some procedures or the use of some resources with programs covered by MFF/TFEU procedures. 
Table 1. (Cont.) Powers and policy concessions obtained by the EP in the RRF regulation.

\begin{tabular}{|c|c|c|c|}
\hline Area & Power & Concessions Obtained by the EP & $\begin{array}{l}\text { Concessions Not Obtained by the EP or } \\
\text { Watered Down }\end{array}$ \\
\hline \multirow[t]{6}{*}{ Policy } & $\begin{array}{l}\text { Spending } \\
\text { priorities }\end{array}$ & $\begin{array}{l}\text { Allocation of } 37 \% \text { of the funds to the } \\
\text { green agenda (it asked for } 40 \% \text { ) and } \\
20 \% \text { to the digital transformation. } \\
\text { More detailed plans, address county } \\
\text { specific recommendations (CSRs), etc. }\end{array}$ & $\begin{array}{l}\text { Investment of, at least, } 7 \% \text { in each of } \\
\text { the six pillars. }\end{array}$ \\
\hline & Funds & $\begin{array}{l}\text { RRF should not substitute national } \\
\text { budgetary expenditure and should } \\
\text { apply principle of no harm. }\end{array}$ & $\begin{array}{l}\text { Complementarity of investments with } \\
\text { funds from international financial } \\
\text { institutions. }\end{array}$ \\
\hline & & $\begin{array}{l}\text { Pre-financing of up to } 13 \% \text { (EP asked } \\
\text { for } 20 \% \text { ) and eligibility of measures } \\
\text { implemented during } 2020 \text { that comply } \\
\text { with rules. }\end{array}$ & $\begin{array}{l}\text { Unused commitments to be assigned } \\
\text { to union budget. }\end{array}$ \\
\hline & & $\begin{array}{l}\text { MS may allocate up to } 4 \% \text { (EP asked } \\
\text { for } 5 \% \text { ) of RRF to technical support } \\
\text { instrument and InvestEU (MFF). }\end{array}$ & \\
\hline & $\begin{array}{l}\text { Policy priorities } \\
\text { and conditionality }\end{array}$ & $\begin{array}{l}\text { Social, sustainable development and } \\
\text { green agenda were reinforced. } \\
\text { Procedures to avoid fraud, corruption, } \\
\text { and conflicts of interest are } \\
\text { incorporated. }\end{array}$ & $\begin{array}{l}\text { Gender equality references were } \\
\text { watered down. Other priorities, too } \\
\text { (but less). } \\
\text { Procedures to ensure compliance with } \\
\text { state aid. }\end{array}$ \\
\hline & & $\begin{array}{l}\text { More specificity regarding assessment } \\
\text { criteria and on actions of the EC. }\end{array}$ & $\begin{array}{l}\text { After Stability and Growth Pact's break } \\
\text { clause ends, EC must propose a } \\
\text { regulation to link RRF with sound } \\
\text { economic governance. }\end{array}$ \\
\hline
\end{tabular}

regulation, and the conditionality (rule of law) regulation. Therefore, to present an accurate account of the empowerment of the EP we also need to look at the outcome of these negotiations.

In the case of the ORD, the creation of new resources to ensure that repayment of the RRF does not affect the regular budget of the Union was a top priority for the EP. The EP repeatedly identified it as a condition to give its consent to the whole package (6). Hence, the Interinstitutional Agreement of 16 December 2020 (2020) includes a binding roadmap for the introduction of several new own resources.

Regarding the MFF, the EP pushed to maintain the level of commitments (to avoid that the RRF had a negative impact on the budget) and to direct funds into certain policy areas ('horizontal issues'). Interviewees coincided that the EP obtained an additional $€ 16$ bn to be allocated to a series of flagship programs selected by the EP (7). Several of them also pointed out the EP's success in this regard (8). This concession was very important for two reasons. First, it compensated the EP for cuts in certain areas and allowed the EP to reinforce some of its policy priorities. Secondly, the EP managed (for the first time) to re-open the allocation of MFF funds and acquired a larger role in the negotiation over distribution of the funds (9). Thus, even if the concession was small in terms of the size, the EP perceived it as an important victory.

Finally, on the conditionality on the rule of law, the EP presented amendments to incorporate this issue in the RRF regulation. In the end, these amendments were not included in the final text, but were largely accepted and incorporated in the Regulation 2020/2092 on a General Regime of Conditionality for the Protection of the Union budget, whose scope includes the recovery funds. Hence, although the EP agreed with the Council on softer language, the EP managed to obtain another policy concession here.

In summary, the overall balance suggests that the EP obtained a wide range of concessions. Thus, although its role in governance of the facility remains limited, the EP managed to expand this, gaining access to information and reinforcing its accountability and scrutiny capacities. More importantly, the EP also exercised a noticeable influence on the policy side, extracting several concessions regarding the funds (amounts and allocations) and shaping the policy priorities that will be pursued through the RRF. Nonetheless, the EP failed to obtain many of its demands. To understand this mixed outcome, the next 
section examines by which mechanisms the EP attempted to expand its powers and the limitations it faced.

\subsection{The Scope and Limits of the EP's Strategies: The EP as a Pragmatic Negotiator}

In this section, we verify whether the EP pursued its empowerment in a way that was consistent with the rational institutionalist approach. We can confirm that the EP used several strategies in order to strengthen its bargaining position and influence the outcome of the MFF-RRF negotiations. Nonetheless, when faced with a series of constraints and limitations, the EP discarded nuclear options and opted for pragmatism, settling for the smaller concessions identified in the previous section.

\subsubsection{The Strategic Repertoire of the EP in Action}

Based on the repertoire of strategies identified in the theoretical discussion, we present compelling evidence that supports the argument that the EP deployed several strategies to reinforce its bargaining position. Thus, during the negotiations, the EP systematically attempted to increase its powers and promote its policy agenda using all the means at its disposal. Such behaviour is in line with the rational institutionalist argument, although, as we will see later on, the EP did not act as a pure power maximiser. In this section, we analyse the use made of each one of the strategies previously identified, examining their potential influence and limits.

\subsubsection{Issue Linkage and the Strategic Exploitation} of Timing

Evidence shows that issue linkage has been a crucial strategy for the EP. The RFF was negotiated in parallel to the ORD, the MFF regulation, and the conditionality (rule of law) regulation. Each of these instruments provided for different EP procedural involvement (as Table 2 summarizes) and created a multidimensional negotiating space combining timing and procedures.

Although the RRF ended up being approved via the ordinary legislative procedure, this procedure was not clear at the beginning of the crisis. The Recovery Instrument was initially based on Article 122 TFEU, which does not reserve any role for the EP. However, the funds of the Recovery Instrument were ultimately connected with both the ORD (authorization and repayment provisions) and the MFF (the funds borrowed by the
Commission will be channelled through funds and programs covered by certain budgetary procedures). Thus, the EP acted to link the different parts of the package under negotiation. In that spirit, the negotiating team highlighted that consent for the MFF would only be granted if they were satisfied with the overall package (10). Hence, the EP only gained an effective role and status as a co-legislator in the RRF Regulation because it successfully linked the ORD with the MFF, opening up space for use of Article 175 TFEU.

Interviews coincide in pointing out the importance of the fact that negotiations of the four issues were connected (11). Coordination among the negotiation teams was strong (12). Issue linkage permitted extending the effects of procedures to different areas or to gain leverage in other negotiations (13). Thus, the veto implied in the EP's consent (MFF) and the delaying power of consultation (ORD) could be extended to the other acts connected with the recovery instrument (14). Moreover, once the EP gained the ability to amend the RRF, it could also negotiate concessions in other pieces of legislation in which it was not a co-legislator. The EP explicitly sanctioned this arena-linking strategy connecting the MFF negotiation with the RRF and the rule of law mechanism in several EP resolutions and press releases (15).

The temporal and substantive overlap of dossiers favoured issue linkage and created a specific time framework that the EP exploited in order to strengthen its own position. However, timing played a role in two different directions. At the start of the negotiations, the EP reached a position much faster than the Council did and also updated it faster after the Commission presented its proposals. Thus, it passed a negotiating mandate in November 2018 (16) and reconfirmed it in October 2019 (17). Similarly, the EP also reacted quickly in response to the Covid-19 crisis, issuing resolutions in April (18) and May 2020 (19) and an additional one in reaction to the EUCO conclusions in July (20). Consequently, it offered to begin the trilateral discussions as soon as possible to be involved in the process from an early stage (21).

However, the possibility of strategically exploiting timing depended also on the Council. The Council took a considerable amount of time to reach a position on own resources, evidencing the difficulty of reaching a compromise among the member states. Nonetheless, once the national governments agreed, the urgency of the situation made time a factor working against the EP. MEPs point out the emergency situation created by Covid-19 (22) as well as the costs in public opinion

Table 2. EP's procedural role.

\begin{tabular}{llll}
\hline Instrument & Legal basis & EP role in decision-making & Date of agreement \\
\hline Own Resources & 311 & Opinion (special legislative procedure) & EP approval 16 September 2020 \\
MFF & 312 & Consent (special legislative procedure) & 10 November 2020 \\
Rule of Law conditionality & $322(1)$ & Ordinary legislative procedure & 17 December 2020 \\
RRF & 175 & Ordinary legislative procedure & 18 December 2020 \\
\hline
\end{tabular}


of delaying the money (23) as key factors of urgency. Unsurprisingly, the EP agreed to fast track the required opinion to complete the legislative process and did not attempt to delay the project. Such a swift response put the ball back in the Council's court (24).

The EP and Council agreed on the MFF on November 10. Evidence does not show that the EP sought to delay approval of the MFF, but whilst the Council was in a hurry to approve it, the EP was not. In the case of no agreement, the previous MFF (2014-2020) with a higher expenditure ceiling would be automatically extended, reducing the cost of non-cooperation for the Parliament (25). Thus, the EP called for activation of a contingency plan in the event of an automatic extension of the past MFF ceilings, recalling that this was an option contemplated in the treaties. The EP repeated its threat (7th trilogue, October 8), warning that it would walk out of the negotiations over the lack of advances regarding the MFF and the funding for 15 flagship programmes if the Council did not move (26).

Early agreement on the MFF meant that the EP could not use the leverage deriving from the MFF over the other pending issue, i.e., the RRF (27). Hence, once again, timing became a factor working against the EP (28), with the Council arguing that a swift approval of the RRF was necessary and that the EP should not block it (29). During the trilateral talks, the Council wanted the EP to accept the deal as it was and pressured for a quick agreement. However, the Hungarian government blocked the agreement over the conditionality of the rule of law, which meant that the Council could not close its negotiations on this regulation. This cancelled the timing advantage of the Council (30) and left more room for the EP, who could present several offers during the subsequent negotiations (31). In summary, evidence does not show the EP used a delaying strategy but, rather, that urgency considerations on the necessity of the RRF weighed heavily in the calculus of EP actors.

\subsubsection{The Veto Threat Strategy}

Documentary evidence shows that invoking the veto threat played a salient role in the EP's strategy. In fact, the EP used the threat from the very beginning of the MFF process: Its first resolutions in March 2018 already warned about it. Hence, leveraging its ability to veto part of the package was always part of the EP strategy rather than the result of a failed attempt at persuasion. Some form of veto threat appears in 22 (34.92\%) of the press releases issued during the negotiations. Moreover, several resolutions and parliamentary documents reflected this idea.

Interviewees confirmed that the MFF veto was part of its negotiating repertoire (32). Even though they coincide in that the EP was more prepared to veto the MFF and rule of law conditionality regulations and less so the RFF (33). The ability to veto the MFF was used not only to try to advance on policy priorities, but also to acquire a larger role in allocation of the funds in the MFF, going beyond the formally accorded role (34). The broad intergroup consensus, explained below, reinforced the credibility of the veto threat.

However, interviews consistently mention a factor that weighed against using the veto and blocking the negotiations: the costs of failing to reach an agreement soon. These costs, which were related to the reaction from public opinion and to a sense of urgency for the arrival of the money, decreased the willingness of the EP to effectively veto the RRF (35).

\subsubsection{Intergroup Consensus}

The evidence examined shows significant coordination among the EP's political groups. Thus, five of the main political groups (EPP, S\&D, Renew, Greens, and GUE/NGL) united and held a common bargaining position at the beginning of the negotiations (reflected in joint letters, press releases, resolutions, etc.), although GUE/NGL ended up abandoning the common front (36). Moreover, the votes on the EP resolutions confirm the existence of a clear parliamentary majority, gaining the support of $60-70 \%$ of the MEPs. In fact, one interviewee considered the majority obtained in Committee on Economic and Monetary Affairs (ECON) and Committee on Budgets (BUDG) unprecedented (37). Finally, these groups explicitly declared their commitment to veto the agreement if it was necessary (letter sent by the presidents of five EP political groups-EPP, S\&D, Renew, Greens, and GUE/NGL - to the EUCO), conditioning approval of the package on the incorporation of some of the EP's priorities.

The presidents of the five largest groups as well as the interviewees perceived the broad consensus as a strong negotiating element (38). Additionally, interviewees acknowledged the existence of a broad consensus as a necessary tool to negotiate with the Council (39). Interviewees indicate that the intergroup consensus was reinforced with the inclusion of the Greens (40). In the early stages of negotiations (i.e., March 2020), this group was not aligned with the three main groups (41). One interviewee reports that the appointment of a new rapporteur played a major role in the inclusion of the Greens to the united front (42). Additionally, the Greens perceived that intra-group differences in the EPP and Renew could prevent a sufficient majority (43), which rendered support from the Greens even more important. This assessment was also shared by an interviewee from the S\&D (44). Moreover, two interviewees from the Greens believed that bringing the group to the table increased the green credentials of the whole package (45). As for other groups, ECR tried to adhere but did not find compromise points (46), whilst an interviewee from ID reports his exclusion from the negotiations and a lack of access to information (47).

According to interviewees, consensus was forged by incorporating topics in the package relevant to the 
different groups (48), while excluding those that could be too divisive (49). Interviewees described the negotiations to establish a common position as very difficult, involving concessions that provoked intra-group tensions (50). Interviewees also highlighted the differences in policy priorities (51), and one of the interviewees explained very clearly that achieving consensus at the committee stage was crucial because it preserved the substantive interests of the different groups (52). For this, interviewees argued that personal relations among rapporteurs played a very important role and were facilitated by maintaining the prior negotiating team from the Reform and Support Programme in the previous legislature (53). Some MEPs suggested that having rapporteurs from member states set to profit more from the facility helped consensus (54). Finally, interviewees agreed that governance of the new RRF was one of the points of consensus among groups (55).

However, interviewees also mention the links with national governments as a limit to intergroup consensus. Interviewees perceived that national needs played a significant part in the calculation of the agreement among parties (56). Similarly, being in the opposition also played a role in the behaviour of some parties (57). Moreover, according to the interviewees, these limits on consensus also applied to governance mechanisms, particularly to scrutiny of the national recovery plans (58).

\subsubsection{Commission-EP Alliance}

Despite precedents and a few references included in the press statements to support the Commission or express common interests (59), interviewees coincide in saying that the Commission was not an ally in this specific negotiation. Rather, they perceived the Commission as following the Council's interests (60), particularly on issues related to governance. However, interviewees reported that the Commission was supportive of the EP's position on certain policy issues, e.g., climate (61). One MEP noted that the relationship also depended on who the Commission's negotiator was (62). According to the interviews, lack of support on governance mechanisms happened because the Commission wanted to preserve its autonomy in implementing measures within the RRF (63).

\subsubsection{The Limits to Power Maximisation and the EP's Pragmatism: If You Do Not Get Governance, Take the Money}

As we discussed in the previous section, the strategies of the EP faced a series of conditions that limited their influence, which partially explain why the EP failed to obtain further concessions. However, a piece of the puzzle is still missing. Why did the EP opt for settling for smaller gains instead of trying to use tougher strategies in an attempt to maximise its powers? Why did the EP opt for pragmatism instead of maximisation?
Interviewees explain the EP's renouncement of seeking additional account-holding powers by combining several aspects. Firstly, the facility itself was an old EP aspiration and, hence, having it and participating in its design already signified a success (64). Moreover, other parts of the budgetary package (i.e., the MFF and rule of law regulation) emerged as a priority, especially increasing the size of available funds (65). Moreover, several MEPs pointed out the EP's success in this regard (66). Given that these demands were partially satisfied, the EP had fewer incentives to block the RRF or any of the other pieces of the package under negotiation.

Secondly, interviewees agree that the most influential governance mechanism, i.e., the possibility of the $E P$ voting on national recovery plans via voting on delegated acts, was unachievable (67) and three of them concede that it was overambitious (68). Moreover, interviewees state that they perceived the Council's position on this issue as unmovable and that this marked the limit to what the EP could achieve (69). Several interviewees attribute this inflexibility to the sensitive nature of the Council's July agreement (70). One interviewee put it more bluntly, mentioning the asymmetry of powers between the Council and the EP (71). Additionally, interviewees also assign an important role to the German presidency in keeping an inflexible position (72).

Against this unified front on the Council, the EP consensus was more limited on this issue. Thus, several interviewees report that, in fact, they were not totally convinced as to the wisdom of fully involving the EP in the main instrument of RRF governance, i.e., scrutinizing each national recovery plan. The former statement is fully subscribed by the S\&D interviewee (73). Nonetheless, second-preferred solutions still gave the EP a preeminent role in governance terms (74).

The EP still had tools to seek a more ambitious deal, even when timing was working against it. Thus, ultimately it could have opted for tougher strategies, such as vetoing or delaying the approval of part of the package. However, in the context previously described, particularly when internal divisions started to arise, these threats were less credible and less feasible. Moreover, the actual use of these strategies (assuming the EP was willing and capable of implementing them) posed two additional problems. Firstly, MEPs perceived the political, reputational, and economic costs of such moves as too high. Thus, interviewees recognised that they were reluctant to implement these strategies given the need to respond to the emergency and out of concerns regarding the perception of public opinion (75). Secondly, MEPs were unconvinced that the use of tougher strategies would guarantee a better outcome. Instead, they could endanger the implementation or success of the facility, an old aspiration of the EP (76).

Moreover, taking the appearance of mentions in EP press statements as a proxy of the salience given to the issue, governance was not the main demand of the EP (being outnumbered by policy concerns, rule of law, size 
of the MFF, or own resources). Additionally, seven interviewees argue that the RRF regulation was not really the end of the negotiation. Instead, they believe that the real battle for governance is yet to come and that they will be able to expand the role of the EP (77). Such a perception also contributes to explaining why the EP was not willing to embark on a costly political battle over an issue that could be discussed later on.

Given the lack of receptiveness on the governance side, EP negotiators looked for alternative concessions within the design of the RRF (78). Interviewees report that on the policy side, the heterogeneity of preferences among governments gave them the opportunity to exploit divisions in the Council (79). Hence, interviewees believe that the outcome of the negotiations includes significant policy gains for the EP (80).

All this seems to point to the notion that the EP could have pressed for further gains on governance, but it was uncertain about its ability to extract a more favourable outcome and was not willing to pay the costs of using tough strategies. Therefore, rather than attempting to maximise its powers, it opted for pragmatism, extracting as many concessions as it could in other areas and settling for smaller gains on governance.

\section{Conclusion}

The RRF negotiations are among the most difficult the EP has faced, due to the number of interconnected issues and the amount of funds under discussion. The EP obtained important policy concessions regarding the RRF (i.e., spending priorities), but failed to obtain a major role in its governance. Thus, its accountability and scrutiny powers over the recovery funds are limited. Nonetheless, the EP did obtain an important concession in terms of governance when the EU institutions agreed to give the EP a seat at the table. Thus, the Parliament's involvement in the design of the RRF and the procedure used to approve it was not guaranteed in the beginning.

We have also provided compelling evidence that the EP acted as a rational actor during these negotiations, implementing several strategies in an attempt to reinforce its bargaining position and increase its influence. Thus, the empowerment of the EP (as limited as it may be judged) was the result of a rational negotiator that systematically pursued its own empowerment.

Nonetheless, we have also found that the EP renounced using tougher strategies in an attempt to maximise its powers, settling for smaller gains. Thus, some conditions favoured the EP's pursuit of a more ambitious outcome. The coincidence of a package of four interlinked dossiers (MFF, own resources, rule of law conditionality, and RRF) led quite naturally to issue linkage that allowed the EP to transfer its procedural powers among them. Additionally, the EP could feint with a veto and the existence of a large supporting parliamentary majority, and its high level of intergroup consensus reinforced the credibility of a veto. Moreover, the structure of the events and the existing institutional arrangements also seemed to benefit the EP. For instance, on November 5 , the Council and the EP struck a deal and the former accepted-although vaguely - some of the most controversial points, such as the rule of law mechanism.

However, timing conditioned the ability of the EP to force an outcome favourable to its best governance option on the RRF. Having closed the MFF and own resources dossiers first, the EP risked taking on huge public opinion costs by appearing to be the institution vetoing the arrival of much needed funds if it pushed its governance demands for the RRF. Thus, the opposition of the Council, the lack of support from the Commission, and some underlying cracks in the unity of negotiators regarding the governance (i.e., the EP's control on the national recovery plans) concur to explain why the EP did not push for its main governance demand. In the face of all these constraints, the EP decided to settle for smaller gains (of all kinds) in order to avoid a high-cost political fight and acted as a pragmatic negotiator.

However, the story may not be over, as several MEPs have reported that the fight over governance is yet to come. The EP has a long history of using newly acquired prerogatives (as limited as they may seem) to further extend them and expand its role. With that in mind, the contribution of our article is threefold. First, it adds evidence to the debate about the self-empowerment of the EP (Farrell \& Héritier, 2007; Héritier et al., 2015; Hix, 2002). Second, it offers a more nuanced version of the rational institutionalist argument. Thus, our findings show that the EP acted as a rational actor during the MFF-RRF negotiations, but one that ultimately emerges as a pragmatic negotiator rather than as a pure power maximiser. Finally, it provides original data (including 13 interviews with key decision-makers involved in the negotiations) on a very recent and very relevant policy development, opening venues for further research.

\section{Acknowledgments}

The authors gratefully acknowledge the funds and support received through the EU's Horizon 2020 Research \& Innovation programme-RECONNECT project (Grant Agreement № 770142). The authors also thank the three anonymous reviewers, the editors of this thematic issue, and all the participants of the ERC Workshop 'Rising to a challenge? 10 years of parliamentary accountability of post-crisis EU economic governance' (10 December 2020) and the BACES III Research Conference on EU Studies (18 December 2020) for their invaluable feedback. Finally, the authors also express their sincere gratitude to all the MEPs and officers that agreed to be interviewed for this article.

\section{Conflict of Interests}

The authors declare no conflict of interests. 


\section{Supplementary Material}

Supplementary material for this article is available online in the format provided by the author (unedited).

\section{References}

Alfé, M. (2007). When the linkage of issues is a weapon: The EP and the new financial regulation. EIPAScope, 2, 23-28.

Benedetto, G., \& Hix, S. (2007). Explaining the European Parliament's gains in the EU Constitution. The Review of International Organizations, 2(2), 115-129.

Brandsma, G. J. (2016). Holding the European Commission to account: The promise of delegated acts. International Review of Administrative Sciences, 82(4), 656-673.

Bressanelli, E., \& Chelotti, N. (2016). The shadow of the European Council. Understanding legislation on economic governance. Journal of European Integration, 38(5), 511-525.

Bressanelli, E., \& Chelotti, N. (2018). The European Parliament and economic governance: Explaining a case of limited influence. The Journal of Legislative Studies, 24(1), 72-89.

Busuioc, M. (2013). European agencies: Law and practices of accountability. Oxford University Press.

Closa, C. (2020). Inter-institutional cooperation and intergroup unity in the shadow of veto: The construction of the EP's institutional role in the Brexit negotiations. Journal of European Public Policy, 27(4), 630-648.

Closa, C. (2021). Planning, implementing and reporting: Increasing transparency, replicability and credibility in qualitative political science research. European Political Science, 20, 270-280.

Costello, R., \& Thomson, R. (2013). The distribution of power among EU institutions: Who wins under codecision and why? Journal of European Public Policy, 20(7), 1025-1039.

Council Decision (EU, Euratom) 2020/2053 of 14 December 2020 on the system of own resources of the European Union and repealing Decision 2014/335/EU, Euratom. (2020). Official Journal of the European Union, L 424.

Council Regulation (EU, Euratom) 2020/2093 of 17 December 2020 laying down the multiannual financial framework for the years 2021 to 2027. (2020). Official Journal of the European Union, L 433I.

Devuyst, Y. (2013). European Union law and practice in the negotiation and conclusion of international trade agreements. Journal of International Business and Law, 12(2), 259-316.

Dionigi, M. K. (2020). The European Parliament's oversight powers in economic governance: Proper scrutiny or a play to the gallery? The Journal of Legislative Studies, 26(1), 74-96.

Dionigi, M. K., \& Koop, C. (2019). Losing out on substance but winning procedurally? The European Par- liament and accountability in crisis legislation. West European Politics, 42(4), 776-802.

European Commission. (2020). Proposal for a regulation of the European parliament and of the Council establishing a recovery and resilience facility (COM/2020/408 final).

European Parliament. (2020). Report on the proposal for a regulation of the European Parliament and of the Council establishing a recovery and resilience facility (Report tabled for plenary A9-0214/2020).

Fabbrini, S. (2013). Intergovernmentalism and its limits: Assessing the European Union's answer to the Euro crisis. Comparative Political Studies, 46(9), 1003-1029.

Farrell, H., \& Héritier, A. (2007). Codecision and institutional change. West European Politics, 30(2), 285-300.

Fasone, C. (2014). European economic governance and parliamentary representation. What place for the European Parliament? European Law Journal, 20(2), 164-185.

Goetze, S., \& Rittberger, B. (2010). A matter of habit? The sociological foundations of empowering the European Parliament. Comparative European Politics, 8(1), 37-54.

Héritier, A. (2017). The increasing institutional power of the European Parliament and EU policy making (Working Paper No. 01/2017). Institute for European Integration Research.

Héritier, A., Meissner, K. L., Moury, C., \& Schoeller, M. G. (2019). European Parliament ascendant. Springer.

Héritier, A., Moury, C., Schoeller, M. G., Meissner, K. L., \& Mota, I. (2015). The European Parliament as a driving force of constitutionalisation (Report for the AFCO Committee of the European Parliament, PE 536.467). European Parliament.

Hix, S. (2002). Constitutional agenda-setting through discretion in rule interpretation: Why the European Parliament won at Amsterdam. British Journal of Political Science, 32(2), 259-280.

Hix, S., \& Høyland, B. (2013). Empowerment of the European Parliament. Annual Review of Political Science, 16, 171-189.

Interinstitutional Agreement of 16 December 2020 between the European Parliament, the Council of the European Union and the European Commission on budgetary discipline, on cooperation in budgetary matters and on sound financial management, as well as on new own resources, including a roadmap towards the introduction of new own resources. (2020). Official Journal of the European Union, L 433I.

Kreppel, A. (1999). What affects the European Parliaments legislative influence: An analysis of the success of EP amendments. JCMS: Journal of Common Market Studies, 37(3), 521-538.

Meissner, K. (2016). Democratizing EU external relations: The European Parliament's informal role in SWIFT, ACTA, and TTIP. European Foreign Affairs Review, 21(2), 269-288. 
Meissner, K., \& Schoeller, M. G. (2019). Rising despite the polycrisis? The European Parliament's strategies of self-empowerment after Lisbon. Journal of European Public Policy, 26(7), 1075-1093.

Moury, C. (2007). Explaining the European Parliament's right to appoint and invest the commission. West European Politics, 30(2), 367-391.

O'Keeffe, M., Salines, M., \& Wieczorek, M. (2016). The European Parliament's strategy in EU economic and financial reform. Journal of European Public Policy, 23(2), 217-235.

Pollack, M. A. (1997). Delegation, agency, and agenda setting in the European Community. International organization, 51(1), 99-134.

Pollack, M. A. (1999). Delegation, agency and agenda setting in the Treaty of Amsterdam. European Integration online Papers (EloP), 3(6), 1-19.

Puetter, U. (2012). Europe's deliberative intergovernmentalism: The role of the Council and European Council in EU economic governance. Journal of European Public Policy, 19(2), 161-178.

Regulation (EU, Euratom) 2020/2092 of the European Parliament and of the Council of 16 December 2020 on a general regime of conditionality for the protection of the Union budget. (2020). Official Journal of the European Union, L 433I.

Regulation (EU) 2021/241 of the European Parliament and of the Council of 12 February 2021 establishing the Recovery and Resilience Facility. (2021). Official Journal of the European Union, L 57.

Ripoll Servent, A. (2014). The role of the European Parliament in international negotiations after Lisbon. Jour- nal of European Public Policy, 21(4), 568-586.

Rittberger, B. (2012). Institutionalizing representative democracy in the European Union: The case of the European Parliament. JCMS: Journal of Common Market Studies, 50, 18-37.

Rittberger, B. (2014). Integration without representation? The European Parliament and the reform of economic governance in the EU. JCMS: Journal of Common Market Studies, 52(6), 1174-1183.

Rosén, G. (2016). A match made in heaven? Explaining patterns of cooperation between the Commission and the European Parliament. Journal of European Integration, 38(4), 409-424.

Schoeller, M. G., \& Héritier, A. (2019). Driving informal institutional change: The European Parliament and the reform of the Economic and Monetary Union. Journal of European Integration, 41(3), 277-292.

Shaohua, Y. (2015). The European Parliament's role in EU trade policy after Lisbon: Analysis from an actorness approach (Online Papers on Parliamentary Democracy, 3/2015). PADEMIA.

Van de Steeg, M. (2009). Public accountability in the European Union: Is the European Parliament able to hold the European Council accountable? European Integration online Papers (EloP), 13(3), 1-24.

Wille, A. (2016). The evolving EU accountability landscape: Moving to an ever denser union. International review of administrative sciences, 82(4), 694-717.

Woźniakowski, T., Maatsch, A., \& Miklin, E. (2021). Rising to a challenge? Ten years of parliamentary accountability of the European Semester. Politics and Governance, 9(3), 96-99.

\section{About the Authors}

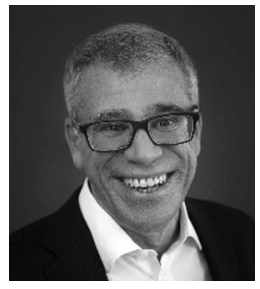

Carlos Closa Montero is Professor at the Institute of Public Goods and Policies, Spanish National Research Council (IPP, CSIC, Madrid) and Adjunct Professor at the School of Transnational Governance, European University Institute (STG, EUI, Florence) and Co-Editor of the European Political Science Review (EPSR). He has been a Jean Monnet Fellow (EUI), Visiting Fellow (Minda de Gunzburg Centre for European Studies, Harvard University), Visiting Professor (College of Europe, Bruges) and Senior Emile Nöel Fellow (Jean Monnet Centre, NYU). He leads the Work Package on fiscal and macroeconomic governance within the H2020 Project RECONNECT Reconciling Europe with its Citizens through Democracy and Rule of Law. He researches on institutional design in EU and regional organizations.

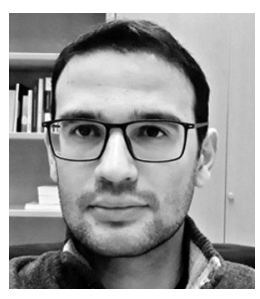

Felipe González De León holds a BA in Political Science and Public Administration (USC), a MSc in Economics (USC) and a MSc in Comparative Politics (LSE). He specialises in comparative political economy and is particularly interested in the study of economic decision-makers and economic governance. Before joining RECONNECT as a Research Associate, he worked in finance and research.

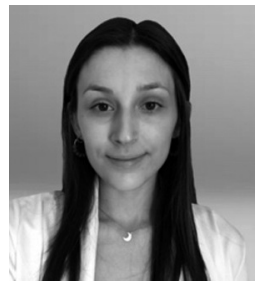

Gisela Hernández González graduated in International Relations (UCM) and holds a Master in European Studies (San Pablo CEU University). She is currently developing her PhD project on rule of law enforcement in the European Union at the IPP-CSIC, and works as a RECONNECT Research Associate. Previously, she worked at the European Council on Foreign Relations (ECFR), Madrid Office, researching on migration and border management issues in the EU. 